\title{
Papel para un Perú independiente: el pensamiento económico español y la creación del Banco Auxiliar de Papel Moneda
}

\author{
Dionisio de HARO ROMERo \\ Universidad Rey Juan Carlos. Madrid \\ dionisio.deharo@urjc.es
}

Recepción: 16 de octubre de 2012 / Revisión: 13 de febrero de 2013

Aceptación: 1 de abril de 2013 / Publicación: diciembre de 2013

\section{RESUMEN}

El artículo analiza la recepción en Perú de las teorías monetarias dominantes en la segunda mitad del siglo XVIII, especialmente las de Adam Smith, a través de autores peninsulares. El trabajo pretende mostrar el caso que lo ejemplifica, el del primer banco del Protectorado, que se cimentó sobre los argumentos de la obra de Alonso Ortiz. Se calibra la importancia del autor en el pensamiento económico de la Ilustración y cómo su obra se conoció y aplicó, con modificaciones, en la primera experiencia bancaria de la independencia.

Palabras clave: historia monetaria, sistema fiduciario, metales precios, independencia del Perú, casas de la moneda, banco emisor, economía, Perú, siglo XIX.

\section{Paper for an Independent Peru: Spanish Economic Thought and the Creation of the Banco Auxiliar de Papel Moneda}

\begin{abstract}
This article analyzes the reception, in Perú, of the dominant monetary theories of the second half of the eighteenth century, especially those of Adam Smith, through the works of peninsular Spanish authors. The paper presents the exemplary case of the first bank of the Protectorate, which was founded upon the reasoning in the works of Alonso Ortiz. The article weighs the importance of Ortiz in the economic thought of the Enlightenment and looks into how his works were known and applied, with modifications, in the first banking experiment of the independent Peruvian nation.
\end{abstract}

Key words: Monetary History, Fiduciary System, Metals Prices, Independence of Peru, Houses of the Currency, Bank Issuer, Economy, Peru, $19^{\text {th }}$ Century.

SuMARIO: 1 . Introducción. 2. Imperio y plata: límites de liquidez en una economía productora de metales preciosos. 3. El referente teórico: el Ensayo económico sobre el sistema de la moneda papel, de José Alonso Ortiz. 4. El Banco Auxiliar de Papel Moneda y la reimpresión del Ensayo económico sobre el sistema de la moneda papel. 5. Conclusiones. 6. Referencias bibliográficas. 


\section{INTRODUCCIÓN}

En el proceso de independencia del Perú se trataron las controversias monetarias y bancarias con enfoques modernos ${ }^{1}$. Las medidas encaminadas a resolver los graves problemas de liquidez que venía arrastrando la economía virreinal, y que se vieron agravados con la guerra de la independencia, respondieron a proyectos de carácter reformista con sugerentes permeabilidades. Desde la perspectiva monetaria la iniciativa más singular fue la representada por el Banco Auxiliar de Papel Moneda. La original experiencia bancaria del Perú significó la primera iniciativa de emisión de papel moneda por parte de una autoridad pública en Sudamérica ${ }^{2}$. Asimismo, el referente teórico adoptado, el Ensayo Económico sobre el sistema de la moneda papel y el crédito de José Alonso Ortiz -publicado en Madrid en 1796 y reimpreso en Lima en 1822- mostró la influencia que tuvo el pensamiento económico español para las autoridades del Protectorado. El artículo pretende responder a interrogantes relacionados con los retos y límites a los que la iniciativa se vio sometida en el contexto de un complejo marco monetario impuesto por la guerra: ¿Qué influencias económicas están detrás de los procesos de reforma? ¿Cuáles son los criterios teóricos de la primera experiencia fiduciaria peruana? y ¿Pueden calificarse como reformas monetarias aquellas iniciativas desplegadas en un marco de guerra dominado por la urgencia fiscal ${ }^{3}$ ?

En el trabajo se atiende a tres cuestiones. La primera plantea el punto de partida monetario y financiero, haciendo hincapié en los graves problemas de liquidez que atraviesa la economía peruana a inicios de la guerra de independencia. La segunda examina el Ensayo Económico de José Alonso Ortiz, referente teórico para el proyecto de banco nacional peruano. Y la tercera procede al análisis comparativo entre ambos. La investigación descubre las dificultades iniciales impuestas por un debilitado y complejo marco monetario general, los errores teóricos de planteamiento, y la débil base social y económica sobre la que se sostiene la nueva institución.

\section{IMPERIO Y PLATA: LÍMITES DE LIQUIDEZ EN UNA ECONOMÍA PRODUCTORA DE METALES PRECIOSOS}

El marco monetario en el que se desenvolvió la economía del virreinato del Perú durante el período colonial tardío estaba caracterizado por la estrecha vinculación y subordinación al sistema monetario y comercial del Imperio español. La producción de metales preciosos era rápidamente transferida desde los principales centros

\footnotetext{
1 Este artículo forma parte del Proyecto de Investigación I+D: El último virreinato. Españay la Independencia del Perú, Referencia HAR2011-23225, financiado por el Ministerio de Economía y Competitividad de España. Agradezco a Ascensión Martínez Riaza y a Víctor Peralta las interesantes observaciones realizadas.

2 En paralelo se crea en Buenos Aires el Banco de Descuentos en 1822. Sin embargo, esta institución financiera limita su emisión a dinero privado, aunque más tarde acabaría transformándose en el banco de emisión del gobierno.

3 En cuanto al análisis del proceso de transición económica y monetaria, para el caso del Perú, puede consultarse en Quiroz, 1993; Contreras, 2004; Mitre, 2004; Gelman, 2009; Irigoin, 2010; De Haro, 2011a; y SALinas, 2011.
} 
mineros hacia la capital del virreinato para su conversión en la ceca limeña en pesos acuñados, con el objeto de atender a la demanda monetaria como contraprestación a las importaciones de lujosas mercancías europeas y a las exigentes reclamaciones de remesas metálicas desde la metrópoli. Asimismo, pesos ensayados y metales en pasta escapaban del circuito oficial sumándose de forma natural al torrente exportador camino de un mercado internacional sediento de plata $^{4}$.

La red monetaria y financiera, constituida por los centros mineros, las Cajas Reales, las Reales Casas de Moneda y el Tribunal del Consulado, conformaban un conglomerado institucional cuya lógica de funcionamiento obedecía fundamentalmente a intereses tradicionales. De un lado, la Corona, principal protagonista del drenaje exterior, subordinaba su actuación a la maximización de las rentas americanas que permitían, tanto el sostenimiento de la onerosa política militar y diplomática en Europa, como la pervivencia de una amplia estructura político-militar de Ultramar a través de los "situados". $\mathrm{Y}$ de otro, los agentes económicos y comerciales que, comprometidos en la defensa de la estructura mercantil de carácter monopolístico, operaban de forma parecida a la Corona en cuanto a la salida de capitales. El virreinato del Perú, junto a Nueva España, desempeñaba la función de un gran corazón bombeando liquidez al servicio de una Europa en pleno proceso de transformación y un espacio asiático con una relación de equivalencia oro/plata que actuaba a modo de imán sobre toda la plata presente en el circuito monetario internacional. Todo ello sostenido desde una estructura imperial agotada y periclitada para los nuevos tiempos económicos ${ }^{6}$.

El "sistema y la política monetaria tradicional" se asentaban sobre la "moneda fuerte" que, o bien tomaba el camino de la exportación 7 , o era retirada de la circulación configurando parte de los "tesoros particulares" ${ }^{8}$, siendo así presa de un intenso proceso de tesaurización ${ }^{9}$. Ambos factores, agravados de forma progresiva por el persistente déficit crónico en la balanza comercial, condenaban a la economía peruana a una continua escasez de metales preciosos y a una paupérrima circulación de monedas de oro y plata, más allá de los puntos críticos de acumulación en Lima que los ciclos de negocios requerían para saldar balances antes de la salida de las flotas del Callao ${ }^{10}$. Asimismo, la política de prohibiciones y rígidas normas de circulación de numerario metálico apenas impedían el intenso tráfico ilegal, que junto a la fuerte corriente exportadora oficial, acababan por prácticamente "secar" los circuitos monetarios internos peruanos durante gran parte del año, siendo habitual, en numerosas transacciones mercantiles regionales, la práctica del intercambio real o la utilización de algún signo de representación primitivo ${ }^{11}$.

\footnotetext{
4 Cipolla, 1999.

5 Marichal, 1999; Espinosa Montero, 2001; García-Baquero, 2003; Prieto - De Haro, 2004, 2010, 2012.

6 Fontana, 1992.

7 Puede producirse "extracción con contrapartida", en el caso del pago de importaciones o "extracción sin contrapartida”, que son las sacas. SARDÀ, 1998 [1948], p. 21.

8 VAdillo, 1846, p. 51.

9 Fenómeno estudiado por MARX, 1976 [1859], pp. 156-168.

10 De Haro, 2006.

11 Observaciones sobre la necesidad de establecer el papel moneda en Lima. Lima, 1821. Colección Documental de la Independencia del Perú (en adelante CDIP), Tomo XIII. Obra de Gobierno y Epistolario
} 
La "política monetaria tradicional" consistente en bajas tarifas de las casas de moneda, altos derechos de acuñación, y equivalencias oro/plata durante el siglo XVIII en torno a $1 / 16^{\prime} 5$, sensiblemente desfasadas con respecto a Europa, subvalorando la plata, y, por consiguiente, defendiendo en el Imperio las existencias de oro, empujaba a la plata a la exportación a gran escala ${ }^{12}$. Esta política no obedeció a principios económicos y monetarios modernos, sino más bien a razones de orden fiscal y defensa de los depósitos tradicionales. De esta forma, se preservaba un sistema monetario incapaz de impulsar el crecimiento económico a través de una oferta monetaria que proporcionase la liquidez suficiente con la que cubrir los tráficos y garantizar las inversiones. Sin embargo, la "política monetaria tradicional", a pesar de considerarse una política absurda y antieconómica ${ }^{13}$, no dejaba de responder a las exigencias y necesidades de una economía de naturaleza tradicional ${ }^{14}$. Es decir, huyendo de anacronismos, los viejos hábitos monetarios eran consecuentes con la demanda de dinero por parte de estructuras económicas propias del Antiguo Régimen. Pero a la vez, su pervivencia suponía crecientes tensiones en un mundo económico internacional que comenzaba a desenvolverse bajo nuevas pautas.

En definitiva, la "política monetaria tradicional", lejos de favorecer la modernización, actuaba como serio obstáculo al mantener una oferta monetaria muy restrictiva ${ }^{15}$. A ello hay que unir la escasa implantación de instituciones financieras y bancarias que supuso un freno para el crecimiento de la economía peninsular y americana ${ }^{16}$. La incapacidad del Estado para responder adecuadamente a la demanda de dinero que de manera natural surgía del proceso de transformación económica fue una constante en el Perú a lo largo de las últimas décadas virreinales, y se agudizó con la independencia. La compleja situación monetaria derivó muy rápidamente, con el inicio de la guerra y la paralización de facto de la Casa de la Moneda de Lima, en una absoluta parálisis del circuito interior ${ }^{17}$. En este complejo entorno de estrechez, exportación y atesoramiento monetario se gestó el Banco Auxiliar de Papel Moneda del Protectorado de San Martín ${ }^{18}$.

de San Martín, Comisión Nacional del Sesquicentenario de la Independencia del Perú, Lima, 1974, p. 256. También véase SALINAS, 2011, pp. 19-29.

12 Puede encontrarse un interesante estudio en torno al bullionismo en VILAR, 1980, pp. 135-163.

13 Luis Ángel Rojo en el prólogo de la última edición de la obra de SARDẢ, 1998 [1948], p. VI.

14 Keynes define el concepto de "economía de intercambio real" en contraposición de lo que sería una “economía monetaria” en la que el dinero desempeña un papel moderno. Véase CHICK, 1990, p. 22.

15 Para el caso de España en el primer tercio del siglo XIX véase PAscuAL - Sudrià, 2008; MaLdonado, 2000 .

16 Cameron, 1974, pp. 17-19.

17 De Haro, 2011b. Al final del ejercicio de 1821 sólo acaban por acuñarse 1.344 .788 pesos frente a los 4.129.500 pesos de media resultante entre los años 1802 y 1815 y 4.001 .608 correspondiente a 1820 . Biblioteca Nacional del Perú, Manuscritos, D1025.

18 Disposiciones de 14-XII-1821 y 7-II-1822. CDIP, Tomo XIII, Obra de Gobierno y Epistolario de San Martín, 1974, pp. 93-94 y 102. 


\section{EL REFERENTE TEÓRICO: EL ENSAYO ECONÓMICO SOBRE EL SISTEMA DE LA MONEDA PAPEL DE JOSÉ ALONSO ORTIZ}

A finales del siglo XVIII José Alonso Ortiz ${ }^{19}$ se convirtió en una figura clave en el pensamiento económico español al traducir al castellano la obra central de la ciencia económica, Investigación de la Naturaleza y Causas de la Riqueza de las Naciones de Adam Smith ${ }^{20}$. Su publicación en 1794 llamó la atención del titular de la Secretaría del Despacho de Hacienda, Diego María Gardoqui, familiarizado con la bibliografía inglesa mercantilista y smithiana por motivos familiares y profesionales ${ }^{21}$. La relación y colaboración entre ambos fue especialmente fructífera para Alonso Ortiz desde el punto de vista de la doctrina económica, y muy en especial la monetaria. Por Real Orden de 14 de noviembre de 1795 Alonso Ortiz fue comisionado por el Ministerio de Hacienda para la elaboración de un dictamen y resumen de las "Leyes Comerciales de Europa" y en 1796 publicó por real cuenta el Ensayo Económico sobre el sistema de la monedapapel y sobre el crédito público. Sin embargo, a partir de 1797, coincidiendo con el cese de Gardoqui como ministro y su nombramiento como embajador en Turín, su trayectoria profesional derivó en una, a veces intensa, en otras errática, carrera diplomática sin nuevas contribuciones significativas a la actividad teórico-económica.

La traducción de la Riqueza de las Naciones y el Ensayo Económico pusieron a disposición del mundo hispánico las aportaciones y el análisis del economista escocés ${ }^{22}$. La última generación de ilustrados incorporaron las ideas de Smith a una extensa y larga bibliografía económica que hundía sus raíces en el arbitrismo español y que tenía como referencia en el siglo XVIII a los agraristas franceses ${ }^{23}$. Ahora bien, la influencia de Smith en España, por diversas razones, no fue importante siendo sustituido rápidamente por Say y Bastiat ${ }^{24}$. Smith no logró romper el cuerpo principal del pensamiento económico español, y la complejidad de su aparato analítico provocó la rápida reorientación hacia obras, que siendo más ligeras, eran a su vez más fácilmente aprehensibles para los liberales del XIX. En cuanto a los territorios de Ultramar, el pensamiento

19 José Alonso Ortiz (Granada, 1755 - Londres, 1815). Estudió Filosofía y Teología en el granadino Colegio del Sacro Monte. Obtuvo el grado en Derecho Civil por la Universidad de Granada en 1778 y en 1784 se incorporó al Supremo Consejo de Castilla. Estrecho colaborador del Secretario de Hacienda, Diego María Gardoqui, inició una amplia carrera diplomática que le llevó a Turín como secretario de la Embajada (1797), y Argel como cónsul general y encargado de Negocios (1803). En la guerra de la Independencia, la Junta Central Suprema le nombra cónsul general en Londres (1809) y en 1815 se le concede el nombramiento de intendente honorario del Ejército. Véase: Fernández marugán - Schwartz, 1978, pp. 394-408.

20 Investigación de la Naturaleza y Causas de la Riqueza de las Naciones, Valladolid, Oficina de la Viuda e Hijos de Santander, 1794. Archivo Histórico Nacional, Legajo 3244. Reimpresión de la obra en Valladolid, 1805 omitiendo la dedicatoria realizada a Manuel Godoy.

21 Diego María Gardoqui (Bilbao, 1735 - Turín, 1798). Comerciante educado en Inglaterra. Director del Comercio de Indias, cónsul interino en Londres, secretario del Despacho de Hacienda (1792-1796) y Embajador en Turín (1796-1798). Merece destacar sus memorias redactadas como Ministro de Hacienda. Véase: Hernández andreu, 1973; Canga Argüelles, 1968 [1826-1827].

22 Según R. S. Smith el abanico de economistas españoles que tomaron como referencia parcial o total el pensamiento smithiano es relativamente amplio: Alcalá Galiano, Valentín de Foronda, Gaspar Melchor Jovellanos, Lázaro de Dou, Ramón Campos, José Canga Argüelles y Álvaro Flórez Estrada, entre otros. SMITH, 1973, pp. 242-253.

23 Para el caso español tendrán una especial relevancia Mirabeau y Herbert.

24 Fuentes Quintana - Perdices, 1997, p. CIII. 
smithiano llegó a través de varios canales: mediante la ordenanza de 1778 que introducía la política de libre comercio, las publicaciones periódicas difusoras de informaciones estadísticas y las ediciones locales de manuales y ensayos de teoría económica, y la adquisición de ejemplares de la obra original por parte de instituciones de carácter gubernativo y corporativo ${ }^{25}$. Asimismo, por razones similares a la experiencia española, la obra de Smith chocó con límites en su recepción relacionados con la comprensión del modelo teórico propuesto y la obstinada censura por parte de las autoridades eclesiásticas que obligaba a importantes mutilaciones en las correspondientes traducciones.

Si Alonso Ortiz a través de la traducción de la Riqueza de las Naciones supuso un punto de inflexión en la recepción de Adam Smith para el hispánico, la elaboración del Ensayo Económico enriqueció los debates en torno a las controversias monetarias en el pensamiento económico español. El autor trató de recoger los elementos fundamentales en los que se articulaba la teoría monetaria smithiana. La idea fuerza que dominó el estudio se centró en las ventajas que suponía para la economía nacional la sustitución de moneda metálica por billetes como medio de abaratar los costes de financiación y transacción, manteniendo como contrapartida un riguroso marco de prudencia y contención monetaria ${ }^{26}$. Su obra recibió el apoyo explícito del gobierno español necesitado de un soporte impreso con el que defender el sistema de vales reales en un momento crítico. El Estado había realizado abultadas emisiones entre 1794 y 1795 y el Banco de San Carlos había procedido a la circulación de billetes sin interés ${ }^{27}$. El papel acumulaba una fuerte depreciación mientras la guerra del Rosellón que enfrentaba a España y Francia entre 1793 y 1795 no dejaba de consumir recursos. En este complejo contexto vio la luz la obra de Alonso Ortiz intentando reforzar la solidez teórica del modelo y explicando la fuerte depreciación del papel en base a factores coyunturales derivados del conflicto. Finalmente, las emisiones masivas de Godoy en 1799 terminaron por quebrar la experiencia financiera española.

Antes de proceder al análisis del Ensayo Económico es preciso concretar dos aspectos que a modo de debilidades manifestó la obra. Por una parte, su defensa cerrada del proyecto de vales reales desarrollado por la Hacienda Real obligó al autor a forzar y obviar aspectos metodológicos relacionados con la teoría monetaria smithiana. Y por otra, la recepción de las tesis de Smith a modo de traducción literal y lineal, sin comprender la relevancia del Libro segundo y, en particular del capítulo tercero titulado "De la acumulación de capital, o del trabajo productivo e improductivo" ${ }^{28}$, impidió establecer el nexo entre la teoría monetaria y el modelo de crecimiento smithiano. Toda la investigación de Smith giraba en torno al citado capítulo, especialmente los apartados dedicados a las controversias monetarias y Alonso Ortiz fue incapaz de percibir la esencia del pensamiento de Smith, entendido como la teorización de un modelo de crecimiento basado en el capital circulante, y en el que la división del trabajo permitía los incrementos de productividad con los que mantener el proceso de acumulación ${ }^{29}$.

\footnotetext{
25 SмITH, 1973, pp. 253-256.

26 Fernández MARUgán - Schwartz, 1978, p. 394.

27 TedDE, 1988.

28 SмIтH, Libro II, Capítulo III, 1981 [1776], pp. 299-317.

29 "Sin duda Smith pretendía que este capítulo se considerara parte central de su libro; los capítulos anteriores nos llevan hacia él, y muchos de los que siguen son sus aplicaciones". Hicks, 1989, p. 34.
} 
Hechas las prevenciones, y para entender el modo en que se trasladaría el modelo al Perú, conviene hacer algunas reflexiones sobre el libro de Alonso Ortiz. El Ensayo Económico estaba compuesto de un discurso preliminar y dos artículos. Uno con el título "Sobre la moneda en general, y sobre la de papel en particular: sus ventajas y desventajas en la pública Negociación", desarrollado en seis capítulos, trataba los temas de la moneda en general, los inconvenientes de la moneda papel, y las utilidades y precauciones con que debía establecerse su implantación por parte de una nación. El otro, denominado "Sobre el Crédito Público", tenía tres secciones dedicadas a los principios generales y efectos del crédito público, y al análisis de los diversos sistemas de endeudamiento nacional.

En el artículo primero Alonso Ortiz desgranó los elementos fundamentales de la teoría monetaria de Adam Smith con el objeto de defender la emisión de moneda papel. Estableció el origen de la moneda en la necesidad de encontrar un "regulante común y nominal" que permitiese representar adecuadamente el valor del trabajo incorporado en las mercancías y así facilitar las correspondientes permutaciones. En este sentido participó de la teoría objetiva del valor y consideró al dinero como cualquier otra mercancía. Para el caso de la moneda el valor central sería el intrínseco, determinante en su valoración internacional ${ }^{30}$. Asimismo, para Alonso Ortiz el análisis basado en la teoría cuantitativa en el que la regulación de los precios estaba directamente relacionada con la proporción entre la masa de metales preciosos y la de las mercancías, no dejaba de ser un sistema ideal, pero falto de solidez y contrastación. No compartió con los cuantitativistas ni el análisis de la formación de los precios ni la consideración de la velocidad de circulación como variable constante ${ }^{31}$; por el contrario, argumentó que los precios monetarios dependían de la oferta y demanda de metales preciosos y que las fluctuaciones en los precios vendrían dadas por alteraciones en los precios del oro y la plata y no por variaciones en la cantidad de dinero. En este aspecto, las autoridades peruanas de la época, en línea con Alonso Ortiz, reflejaron una mayor preocupación por la desvalorización del papel moneda que por supuestas tensiones inflacionistas más acordes con los postulados monetaristas ${ }^{32}$.

Alonso Ortiz debía sortear la paradoja consistente en la defensa cerrada del concepto de dinero mercancía como "regulador universal", y la elección del papel como soporte de un nuevo numerario sin valor intrínseco. En primer lugar, pasó a citar las tipologías de papel moneda: letras de cambio, billetes de banco, notas promisorias, cuentas de caxa, monedas de banco y vales de tesorería ${ }^{33}$. Y es en esta última en la

\footnotetext{
30 Alonso Ortiz, 1796, pp. 33-35.

31 "Una sola pieza de metal como Moneda hace circular con la repetición de su cambio el valor de infinidad de piezas, como si estas existiesen real y separadamente en la circulación, comparada la gran masa de las mercaderías todas con la gran masa del oro y la plata haría que la cosa valiese, por ejemplo, diez; y comparada después con los mismos metales en razón de signos, valdría la misma cosa mil ó más”. Ibídem, p. 48.

32 No repararon tanto en el problema derivado del volumen de emisión como en las dificultades por mantener la cotización del papel moneda a la par con la plata. Operación de extinción del papel moneda a través de la venta de fincas del Estado y loterías. Lima, 1823. Archivo General de la Nación (en adelante AGN), Fondo Republicano, Ministerio de Hacienda, Caja 1, O. L. 9-65.

33 Letras de cambio: arbitrio para pasar caudales particulares a distintas plazas. Billetes de banco: billetes emitidos por Montes de Piedad, Bancos y Compañías de acciones. Notas promisorias: billetes emitidos por bancos derivados del descuento de letras de cambio. Cuentas de caja: préstamo concedido por un banco
} 
que el autor fijó su máximo interés ${ }^{34}$. Para Alonso Ortiz el verdadero papel moneda era aquel que incorporaba la facultad gubernativa para pagamento legítimo de toda deuda, cuyo nominal descansaba sobre la autoridad pública que lo emitía y que en cualquier circunstancia operaba como moneda efectiva del país. Y en segundo lugar, presentó las desventajas que se derivaban del papel moneda relativas a la ausencia de valor intrínseco, la circulación limitada al interior de las fronteras, la relación inexorable entre emisión fiduciaria y exportación de metales preciosos, la posibilidad de emisiones sin límites predeterminados, la tensión inflacionista, y la dificultad en la fijación del interés.

Es el capítulo quinto, "Sobre las utilidades y ventajas de la moneda papel", probablemente el más interesante desde la perspectiva de la teoría monetaria. Alonso Ortiz en este capítulo central entró a resolver la citada contradicción analizando las ventajas relacionadas con el papel moneda y presentando el método por el cual eran superadas las debilidades del sistema de emisión fiduciaria. La aportación más relevante para una nación que optaba por este tipo de emisión estaba relacionada con la sustitución del oro y la plata como materias de amonedación de alto coste. Sujeto al marco establecido por Adam Smith, identificaba la riqueza nacional con el sumatorio de salarios, rentas y beneficios, distinguiendo entre renta total, compuesta por el producto de la tierra y el trabajo de los individuos, y renta neta, la que restaba después de deducidos los gastos precisos para mantener el capital en estado productivo ${ }^{35}$. Para Alonso Ortiz toda inversión que mejorase, perfeccionase y generase ahorros en el mantenimiento del capital productivo provocaría aumentos en la renta neta que, a su vez, incrementaría la riqueza de la nación. En este caso, la moneda metálica, siendo capital circulante, se asemejaba al capital fijo ya que al considerarse un instrumento que facilitaba la distribución no podía formar parte de la "renta pura de la nación". Asimismo, en su equiparación como capital fijo, su mantenimiento como instrumento de circulación implicaba necesariamente la dedicación de una parte importante de la renta que de otro modo pudiera dedicarse a otros fines. De esta forma, cualquier ahorro conllevaría a la disminución en los gastos de acumulación y el consiguiente estímulo para el gasto y la inversión en la economía nacional ${ }^{36}$. De forma complementaria, la salida al exterior de la moneda metálica supondría un aumento equivalente de las importaciones, resultando un shock adicional para la renta nacional ${ }^{37}$. Esta idea

o compañía en "notas promisorias" a clientes de crédito reconocido. Monedas de banco: dinero bancario generado por Bancos de depósito. El modelo de referencia es el Banco de Amsterdam, tratado extensamente por Adam Smith. Véase Smith, 1981 [1776], p. 431; Kindleberger, 1988, pp. 68-69; y PARKer, 1979, pp. 426428. Vales de tesorería: dinero que circula en papel, autorizado por el gobierno y legitimado por el mercado mediante la negociación entre sí simbolizando moneda efectiva y haciendo abstracción del valor intrínseco. Ejemplos de vales de tesorería son: las "cédulas de giro" en la Colonias Americanas Inglesas, los "asignados" franceses, los billetes del Echiquier ingleses, y los vales reales españoles (Vales, Medios Vales de Tesorería emitidos en España desde 1780).

34 "El que en mi sentir debe llamarse propiamente tal". Alonso OrTiz, 1796, p. 76.

35 Sмiтн, Libro II, Capítulo II, 1981 [1776], pp. 259-265.

36 Alonso Ortiz, 1796, pp. 110-111.

37 Smith se refiere fundamentalmente a bienes de equipo demandados por sectores emprendedores. Asimismo supone que la importación de bienes de lujo a penas se vería afectada: "La demanda de bienes extranjeros por parte de estos sectores ociosos de la colectividad, la misma, o casi la misma que era antes". SмIтн, Libro II, Capítulo II, 1981 [1776], p. 267. 
estuvo muy presente en la experiencia peruana en el objetivo de impulsar las importaciones con el objeto de mejorar el nivel técnico y que éstas pudieran realizarse con bajos precios relativos ${ }^{38}$.

Alonso Ortiz recomendaba una emisión fiduciaria limitada mediante la elección de los "vales de tesorería" como moneda papel, que implicase una extracción metálica moderada ${ }^{39}$ y permitiese el afloramiento de oro y plata comprometidos en el atesoramiento particular. Todo el proceso, en el que el papel moneda desempeñaría una función articuladora permitiendo alcanzar objetivos fiscales en un marco de estabilidad monetaria, estaría guiado por el Estado a modo de "mano oculta" ${ }^{40}$. En el caso peruano la preocupación por los capitales "guardados" y la forma de hacerlos aflorar constituyó parte de la centralidad del proyecto bancario ${ }^{41}$.

Sin embargo, quedaba una última pieza por encajar. ¿Qué entendía Alonso Ortiz por emisión fiduciaria apropiada? Su propuesta tuvo un componente de ambigüedad. Si en el "dinero mercancía" el valor intrínseco actuaba a modo de fianza, en la moneda papel era el crédito público el que hacía la función de "ancla". La moneda papel tenía como objeto cubrir en la oferta la circulación metálica drenada pero en ningún caso ensanchar el "canal de la circulación". En caso contrario, una abusiva emisión derivaría en una expulsión del exceso en plata ó en moneda papel, perdiendo ésta la condición de instrumento circulante y convirtiéndose en un fondo muerto y oneroso $^{42}$.

Ante la dificultad de un cálculo a priori del nivel apropiado de emisión, el autor era partidario del seguimiento puntual en el mercado de la cotización de la moneda papel y la demanda de plata. Una demanda de plata a la par con la de papel indicaría el punto de equilibrio ${ }^{43}$. Asimismo, señaló la importancia de tener en cuenta la estructura económica y social de cada país. Es decir, sólo una nación con alto nivel de mercantilización, que dispusiese de una balanza comercial favorable y de un Estado con crédito público saneado, estaría en condiciones de sostener un pleno sistema fiduciario ${ }^{44}$. En caso contrario, era favorable a proceder de un modo pausado y progresivo en la emisión, estableciendo fases iniciales de limitado volumen y estrecha subordinación circulatoria con respecto al efectivo metálico.

Finalmente, como mecanismos de contención el autor consideró útiles la restricción de la circulación del papel moneda al mercado entre comerciantes y con alta

38 Adicción al Capítulo II. "De los diferentes valores de moneda". Alonso Ortiz, 1822, p. 167.

39 Alonso OrTiz, 1796, p. 115.

40 Ibídem, p. 124.

41 Adicción al Capítulo V. "Sobre las utilidades y ventajas del papel moneda". Alonso Ortiz, 1822, p. 173.

42 Como ejemplo histórico, tomado a su vez de Adam Smith, de los efectos no deseados de una excesiva emisión de moneda papel, cita el proyecto de Law aprobado por la corona francesa en 1720, compartiendo las críticas de Mr. Du Tot en su obra Réflexions politiques sur les Finances et le Commerce, ou lón éxamine quels ont été les revenus, les denrées, le change étranger et conséquemment sur notre commerce, les influences des augmentations et des disminutions des valeurs numéraires des monnoyes, La Haya, 1745. Alonso OrTIz, 1796, p. 147.

43 Como así recoge su análisis de la experiencia española de los Vales Reales, en el que las fluctuaciones en la cotización de los títulos estarían vinculadas más a los shocks bélicos que a sobreofertas en el mercado. Ibídem, pp. 169-177.

44 Ibídem, 1796, p. 157. 
denominación nominal ${ }^{45}$ y la dotación de fondos de amortización. Con respecto a los fondos, Alonso Ortiz defendió la creación de un "fondo de reducción" consistente en una quinta parte del fondo principal en efectivo ${ }^{46}$ que respondiese a reducciones ocasionales, y un "fondo de extinción", materializado en una parte individualizada del caudal público del Estado. El "fondo de reducción" sería establecido por el gobierno o los bancos y compañías de crédito vinculados con éste cobrando un moderado interés por descuento. De esta forma, la demanda de plata quedaría reducida a los tenedores con urgencia de efectivo que a su vez se verían liberados de agiotajes abusivos del mercado. En cuanto al "fondo de extinción", el gobierno respondía en su condición de deudor a través de un fondo de seguridad consistente en el blindaje de una parte del caudal público a modo de hipoteca. La finalidad era recurrente con respecto al primer fondo, garantizar el valor nominal en el mercado reforzando la confianza por parte del público ${ }^{47}$. Por el contrario, en la experiencia peruana estuvieron ausentes estos tres últimos elementos: progresividad en función del nivel de mercantilización, restricción de la circulación entre comerciantes y la disponibilidad de efectivos fondos de reducción y extinción. Una fatal trilogía para el funcionamiento estable de la iniciativa monetaria.

$\mathrm{El}$ artículo segundo consistió en un detallado análisis en torno al crédito público. Según Alonso Ortiz, era común que aquellos economistas que argumentaban a favor de la moneda papel fuesen a su vez partidarios de la extensión del crédito público y vicever$\mathrm{sa}^{48}$. En coherencia con el artículo primero manifestó un entusiasmo comedido en torno a la extensión del endeudamiento público afirmándose en posiciones muy moderadas. Prueba de ello era su idea contraria al encadenamiento de deudas por parte del Estado que pudieran superar los límites de la renta neta y afectar en el largo plazo al crecimiento económico ${ }^{49}$. En definitiva, el nivel de deuda debía guardar estrecha relación con la cantidad de papel que el país podía mantener en circulación de forma estable.

45 Adam Smith desaconsejaba la circulación de billetes con valor menor a 5 libras esterlinas, con el objeto de proteger la circulación metálica en esferas sensibles y alejar del sistema posibles perturbaciones motivadas de gestiones ineficientes. Smith, Libro II, Capítulo II, 1981 [1776], pp. 291-293.

46 "Un gobierno que necesitase, por ejemplo, despachar sus Billetes hasta en cantidad de quince millones de pesos, y que estos cupiesen sin pérdida en la circulación del país sin el auxilio del fondo de reducción, podría hacer correr veinte millones con el mismo aprecio que los quince, tomando empréstitos hasta la suma de veinte, y reservando cinco para el fondo dicho". Alonso OrTiz, 1796, p. 210.

47 Real Decreto de 29-V-1792, sobre arbitrio de los sobrantes de Propios; Real Decreto de 12-I-1794, nuevo arbitrio sustituyendo al anterior; Real Decreto de 29-VIII-1794, aumentando el fondo con los 7 millones de subsidio extraordinario del estado Eclesiástico; y Real Decreto de 5-VIII-1795, tratando la misma materia. Ibídem, pp. 216-217.

48 Antonio Genovesi, alejado del ideario mercantilista con relación a las posiciones bullonistas, abogaba en su Lezioni di Commercio por la virtualidad del crédito púbico. Más decidido se manifiestaba en su obra Thomas Mortimer, Elements of Commerce, Politics and Finances, considerando los fondos acumulados por el Estado en forma de deuda pública y renovados mediante el pago en interés, de un nuevo caudal que se sumaba a la circulación con efectos positivos sobre la actividad productiva. Por el contrario, Richard Price en su libro An Apple to The Public on the Subject of The National Debt rechazaba el sistema de endeudamiento público considerando al Estado como mero competidor con el sector privado en la captación de fondos prestables. Por su parte, David Hume recogía en The State of the Public Debt and Finances in 1783 la consideración de la deuda pública como un mecanismo al servicio de agentes rentistas, abocado a crisis cíclicas, y de difícil acomodo a tasas de crecimiento moderadas.

49 Alonso Ortiz, 1796, p. 287. 


\section{EL BANCO AUXILIAR DE PAPEL MONEDA Y LA REIMPRESIÓN DEL ENSAYO ECONÓMICO SOBRE EL SISTEMA DE LA MONEDA PAPEL}

Con el objeto de comprender la decisión de crear un banco de emisión por parte del primer gobierno del Perú independiente es preciso analizar el marco económico y financiero general del virreinato en sus últimos lustros. A partir de 1808 el sistema económico colonial fue sumando sucesivos desajustes y dislocaciones que lo conducirán en 1820 a un punto de irresoluble continuidad. El panorama económico del Virreinato desde principios del siglo XIX venía caracterizado por el estancamiento, dejando atrás el último ciclo de expansión de fines del XVIII asentando sobre la floreciente minería del Bajo Perú ${ }^{50}$ y la expansión demográfica ${ }^{51}$. A pesar de la fragmentación y la errática disponibilidad de datos cuantitativos durante este período, podemos constatar la tendencia decreciente en la práctica totalidad de los sectores económicos a través de los datos que nos suministran las fuentes del comercio registrado y la recaudación de impuestos ${ }^{52}$. El resultado de esta dinámica tenía una doble vertiente. Por un lado, un acusado déficit comercial superado con crecientes salidas de capital monetario, y por otro, una abultada deuda pública ajustada mediante heterodoxas operaciones financieras ante la incapacidad por parte de la administración de acompañar los incrementos de gastos mediante ingresos corrientes $^{53}$. Ambos vectores condujeron a la economía virreinal a largo plazo al estancamiento y la falta de liquidez. Para la dinámica antes descrita valga de ejemplo ilustrativo el sector minero, auténtico monocultivo de la economía virreinal y actividad clave por sus "enlaces anteriores" y papel predominante en los circuitos comerciales, que en el período correspondiente a 1816-1820 sufrió una caída de más del $30 \%{ }^{54}$.

En cuanto a la deuda pública, la Hacienda Real, con motivo del ciclo de guerras que se inició en 1796 hasta su culminación en 1824, se vio sometida a una demanda de fondos con los que atender las necesidades militares que pronto desbordaron los techos fiscales alcanzados con las reformas borbónicas del siglo XVIII ${ }^{55}$. Las bases fiscales manifestaron límites de crecimiento relacionados con el estancamiento económico y la atonía comercial. Los virreyes Fernando Abascal (1806-1816) y Joaquín de la Pezuela (1816-enero/1820), mediante una política de alianzas fiscales con las élites locales ${ }^{56}$ aprobaron un conjunto de iniciativas financieras heterogéneas con el objetivo de detraer fondos con los que hacer frente a las urgencias militares. El creciente endeudamiento se convertía en un elemento clave de estabilización para unos gobiernos agobiados por unos gastos en continuado ascenso que nunca lograban cubrirse a pesar de los considerables incrementos impositivos ${ }^{57}$.

\footnotetext{
50 FISHER, 1977.

51 Tepaske, 1986, pp. 327-332.

52 Chocano, 2010, pp. 19-101.

53 AnNa, 2003.

54 Contreras, 2010, p. 157.

55 KLEIN, 1998, p. 18. En cuanto a la relación entre revoluciones y presión fiscal, véase O’Phelan, 1988.

56 HAMnETt, 2000, pp. 8-9.

57 Flores GuZmán, 2010, pp. 334-335 y 355-358.
} 
Los sucesivos déficit fiscales ocultos en los informes oficiales, al no registrarse los gastos no cubiertos en las cuentas de las cajas reales, acabaron por conformar una deuda financiera ascendente a 12 millones de $\operatorname{pesos}^{58}$. Este proceso fue posible mediante la transformación de la estructura crediticia tradicional por una nueva arquitectura financiera articulada desde el Estado con la participación activa de intereses comerciales, que puso a disposición de la administración la mayoría de los fondos susceptibles de ser prestados ${ }^{59}$. Sin embargo, este factor de estabilización acabó convirtiéndose a finales del período colonial en un lastre imposible de atender por una economía agotada.

En el tiempo del Protectorado (30 de agosto de 1821 a 20 de septiembre de 1822), San Martín y su primer gobierno emprendieron una intensa remodelación del organigrama político administrativo. Un objetivo prioritario era hacer frente a fuertes necesidades de financiación contando con una economía en estado estacionario, y una deuda pública y exterior insoportable para un marco crediticio y financiero tardo colonial desbordado. En una primera fase se esperó hacer uso de la Casa de la Moneda de Lima, y de la materia prima, la plata, con la esperanza de resolver los problemas inmediatos de liquidez. Sin embargo, pronto chocó con un límite insalvable a corto plazo: "máquinas sin plata". Es decir, aun disponiendo de las infraestructuras con las que acuñar moneda, la falta de metales, con los yacimientos y rutas de aprovisionamiento bajo control realista, mantenía cortado el nervio del nuevo Estado. Todos los intentos por reactivar la Casa de la Moneda fueron en vano ${ }^{60}$, y en el otoño de 1821 el Protectorado asistía impotente a un posible colapso administrativo.

En este complejo marco, y cegada la vía del endeudamiento bajo el modelo virreinal, el gobierno de San Martin gestó la creación del Banco Auxiliar de Papel Moneda. El modelo proyectado de sistema fiduciario aspiró a emular a los sistemas financieros y de crédito europeos, situando la iniciativa más allá de la mera superación de las urgencias fiscales provocadas por la guerra. La pretendida reforma ambicionaba sentar las bases del futuro Banco del Perú con fuerte capacidad crediticia, amplia presencia geográfica y funciones propias de máxima autoridad monetaria.

La paternidad del proyecto ha sido objeto de un intenso debate historiográfico. Mientras Emilio Dancuart y José de la Riva Agüero se inclinaban a favor de Hipólito Unanue, Carlos Camprubí la atribuía a San Martín ${ }^{61}$. San Martín precisaba de dinero del que no disponía para poder continuar el esfuerzo bélico y encomendó la tarea a su ministro de Hacienda, que se vio en la urgencia de impulsar la iniciativa y articular el proceso político y técnico que llevaba aparejada. Pero San Martín no reunía las condiciones objetivas para que se le pueda atribuir la concepción del proyecto; y Unanue, a pesar de ocupar los más altos cargos de responsabilidad gubernativa en el ámbito económico y hacendístico, no disponía de una base teórica y

\footnotetext{
58 ANNA, 2003, p. 154.

59 Quiroz, 1993, pp. 79-149.

60 Tesorería de la Casa de Moneda. Lima, 1821. AGN, Fondo Republicano, Ministerio de Hacienda, Caja 1, O.L. 9-1-a/b; 9-4-a/b; 9-2; y 9-7-a.

61 Dancuart, 1905; Riva Agüero, 1953; Camprubí, 1960.
} 
formativa lo suficientemente sólida como para atribuirle la autoría de una iniciativa $\tan$ compleja ${ }^{62}$. En diversos pasajes el propio ministro reconocía sus importantes limitaciones en los asuntos económicos ${ }^{63}$, y repasando los fondos de su biblioteca personal, que aparecen recogidos en su memoria testamentaria ${ }^{64}$, se advierte que la presencia de obras de carácter económico era marginal y destacaban únicamente dos autores de referencia, como son Gaspar Melchor de Jovellanos y Jean-Batiste Say ${ }^{65}$. A ello se suma que en el Perú de la independencia hubo una significativa escasez de capital humano con elevados conocimientos económicos, lo que tiene que ver con la ausencia de una masa crítica y el limitado grado de recepción y penetración de las controversias y debates económicos de carácter internacional en el virreinato de finales del siglo XVIII y principios del XIX ${ }^{66}$. En este sentido, la historia de la Sociedad de Amantes del País y del Mercurio Peruano ${ }^{67}$ y la información que proporciona la prensa doctrinal desde 1811 a 1820 ofrecen un resultado muy modesto en relación a lo que fue la recepción y conocimiento de las aportaciones de la época a la ciencia económica ${ }^{68}$. Esta debilidad es aún más patente en aspectos monetarios y financieros, sólo perceptibles de forma colateral y tratados bajo una óptica tradicional. En definitiva, los debates monetarios en torno a los bancos de emisión y el papel moneda se precipitaron con la guerra, con escasa base teórica asimilada y sin previa experiencia institucional ${ }^{69}$, en un momento crítico que requería rápidas respuestas y medidas de urgente implantación.

En este complicado marco general el diseño del proyecto del Banco recayó finalmente sobre un reducido grupo de personas. El gobierno, agobiado ante la escasa

62 José Hipólito Unanue y Pavón (Arica, 1755 - Cañete, 1833). Naturalista, político y reformador de la medicina. Profesor en medicina de la Universidad de San Marcos (1788), cooperó en la formación de la Sociedad de Amantes del País (1790) y colaboró activamente a través de diversas publicaciones en El Mercurio Peruano. Fue principal impulsor de la creación del Colegio Médico de San Fernando (1815) y participó, por parte del virrey, en las negociaciones de Miraflores de 1820. Tras la proclamación de la Independencia es nombrado ministro de Hacienda y en el Congreso Constituyente participará activamente en la redacción del proyecto de Constitución de 1823. Para San Martín, véase Lynch, 2009.

63 "Aquí se han gastado 400 mil duros con el paso del ejército, y en Arequipa quinientos setenta mil [...] Yo he visto las cuentas y al parecer están arregladas; porque yo ni soy contador ni entiendo de economía”. Carta de Hipólito Unanue al Presidente del Consejo de Gobierno. Cuzco, 22-VII-1825. CDIP, Tomo I, vol. 7, Los Ideólogos. Hipólito Unanue, 1971, p. 628.

64 Memoria a la cual deben arreglar mi testamento mis albaceas doña Jesús Unanue y Don Francisco Mata Linares, nombrados en el poder para testar que otorgue ante D. Gerónimo Villafuerte en 12-X-1831. Lima, 1831. CDIP, Tomo I, vol. 7, Los Ideólogos. Hipólito Unanue, 1971, pp. 136-140.

65 La corta lista de libros económicos responde a las siguientes entradas: Política y comercio del Támesis (sin precisar autor), Ley Agraria de Jovellanos, Diccionario de Economía Politica (sin precisar autor), Economía y Política de Say, y Principios de Economía Política (sin precisar autor, aunque podría tratarse de la obra de David Ricardo).

66 Hipólito Unanue en sus cartas precisa las dificultades a la hora de contar con personal cualificado para el Ministerio de Hacienda. Documentos de carácter patrimonial, 1763-1833. CDIP, Tomo I, vol. 7, Los Ideólogos. Hipólito Unanue, 1971, p. 581.

67 Véase Clément, 1979.

68 La ideología económica "mercurista" queda bien definida en el concepto neomercantilista. Véase, LÓPEZ SORIA, 1971, p. 113. Asimismo, no se manifiestan grandes cambios a través de la prensa doctrinal de principios del siglo XIX, manteniéndose posiciones cercanas al concepto antes indicado. Véase MARTíNEZ RIAZA, 1985.

69 Quiroz, 1995, pp. 105-106. Lejos quedan los ecos de la banca pública del siglo XVII, véase SuÁREZ, 2001. Asimismo los casos de bancos de avíos mineros como el Real Banco de Rescate de Potosí no nos sirven como modelos precedentes por su tipología y funciones. 
disponibilidad de fondos con los que poder consolidar su precaria existencia y con el objetivo de encontrar vías de financiación estables, llamó a consultas a las dos principales instituciones de Lima: el Tribunal del Consulado -suprimido en $1822^{70}$ y sustituido en el Protectorado por la Cámara de Comercio- y la Municipalidad ${ }^{71}$. Por parte del Tribunal del Consulado sus representantes fueron: Andrés Salazar, José Antonio Palacios, Antonio Álvarez de Villar y Pedro Abadía ${ }^{72}$. Por parte de la Municipalidad ${ }^{73}$ se designó a cuatro electores para participar en las negociaciones con el Ministerio: Francisco Moreyra y Matute, Diego Aliaga, Tiburcio de la Hermoza y Miguel Antonio Vértiz. La idea del banco emisor comenzó a abrirse paso e Hipólito Unanue, con la finalidad de concretar el proyecto y sumar complicidades, citó en Palacio el 22 de noviembre a cincuenta personalidades representativas de la vida económica limeña, en que propietarios y hacendados principales ocuparon lugar destacado ${ }^{74}$. En la última fase preparatoria, durante el mes de diciembre, trabajaron en paralelo dos comisiones técnicas. Una, designada por la Municipalidad ${ }^{75}$ encargada de establecer las garantías precisas para respaldar la emisión de billetes; y otra nombrada por San Martín a instancias del Tribunal del Consulado ${ }^{76}$, centrada en el diseño de las condiciones financieras y económicas de la nueva entidad emisora. Fue esta última comisión la que ideó y acabó dando forma al proyecto del banco emisor ${ }^{77}$. No extraña que fuese el grupo social y económico vinculado al Tribunal del Consulado el promotor de la iniciativa monetaria. Por una parte, disponían algunos de sus miembros del acervo económico básico en el ámbito financiero ${ }^{78} ; \mathrm{y}$ por otra, tenían un vasto conocimiento de la realidad y las prácticas monetarias del virreinato, adquiridas a través de la experiencia comercial y mercantil del propio Tribunal. La futura dirección del Banco, impulsora de la reimpresión en Lima del Ensayo Económico de José Alonso Ortiz, surgió de este entorno ${ }^{79}$.

70 Mazzeo, 2006, pp. 63-85.

71 El modelo que se pone en marcha sigue la senda ya marcada por los últimos virreyes basada en el establecimiento de pactos con las élites económicas que permitieran contar con su apoyo y colaboración en situaciones críticas. HAMNETT, 2000.

72 Tribunal de Consulado, 30-X-1821. CDIP, XXI, Asuntos Económicos, vol. I, Informes y Oficios del Tribunal del Consulado, 1971, p. 72.

73 Formada por los mismos miembros que integraban el Ayuntamiento constitucional tras las elecciones de finales de 1820. Gamio, 2005 [1944].

74 Por parte de la Municipalidad destacan el: marqués de Montemira, conde de Casa Saavedra, marqués de Casa Dávila, conde Vista Florida, conde de las Lagunas, conde de Torre Antigua, conde del Villar de Fuente, conde de Lurigancho, y marqués de San Miguel.

75 José Ma Galdiano, Manuel Antonio de Vértiz, conde del Villar de Fuente, Dámaso de Arias y Sanz de Santo Domingo.

76 Andrés de Salazar, Pedro Abadía, Diego de Aliaga, Matías Maestro y Antonio Álvarez del Villar.

77 Idea de un Banco Auxiliar. Lima, 1821. CDIP, Tomo XIII, vol. I, Obra de Gobierno y Epistolario de San Martín, 1974, pp. 248-265.

78 Prueba de ello es el elaborado dictamen de 1823 que Antonio Álvarez del Villar eleva al ministerio de Hacienda con el objetivo de amortizar papel moneda por moneda de cobre, basándose teóricamente en economistas de relevancia internacional como es el caso de J. Batiste Say y demostrando su detallado conocimiento. AGN, Fondo Republicano, Ministerio de Hacienda, Caja 1, O.L. 77-8-9-10.

79 Se nombró como director del Banco al conde del Villar de Fuente, y como tesorero y contador a Andrés Salazar y Antonio Álvarez, respectivamente. CDIP, XIII, Obra de Gobierno y Epistolario de San Martín, 1974, circular de 27-VIII-1821, p. 94. 
Por otra parte, Carlos Camprubí, el principal conocedor de la historia de los bancos en el Perú, sostuvo la idea de la fundación de la nueva autoridad monetaria desde una potente base social y económica nítidamente comprometida con las corrientes independentistas ${ }^{80}$. En cambio, la reciente investigación nos muestra un complejo proceso de gestación sujeto a intereses y objetivos diversos por parte de las dos instituciones implicadas. Por un lado, buena parte de la Municipalidad de Lima, garante de los viejos intereses terratenientes y temerosa del caos y la anarquía que acompañaban a la guerra, veía en las nuevas autoridades la oportunidad de ejercer un rol que el poder virreinal mantuvo embridado. De esta forma, la Municipalidad con su presencia legitimaba a las nuevas autoridades, y garantizaba la estabilidad del gobierno. Sin embargo, el pacto ofrecido por la élite criolla no incluía la liberación masiva de fondos, máxime en un momento en el que el desenlace de la guerra todavía era incierto. Por otro, el Tribunal del Consulado, sensiblemente disminuido tras la retirada del Virrey, sustentó una posición de colaboración forzosa con el Protectorado con el objeto de defender los intereses comerciales tradicionales en el nuevo escenario nacional. En definitiva, el Banco se impuso desde el gobierno sin el compromiso explícito de los influyentes sectores sociales y económicos limeños, que acabaron por percibir la iniciativa como una mera oficina fiscal de los independentistas. Sin olvidar que el nuevo nervio de la guerra dependía de la plata enterrada en el interior del país que esperaba de campañas militares exitosas, y no de una supuesta base económica que no terminó por liberar los avales a la nueva entidad $^{81}$. El Banco Auxiliar de Papel Moneda disponía de un tiempo escaso que desde el primer instante corrió en su contra.

Hasta el momento, las interpretaciones en torno al fracaso del Banco, incluyendo la de Camprubi, se han centrado en aspectos relacionados con la falsificación, la falta de condiciones objetivas, el excesivo volumen de emisión, los sistemáticos incumplimientos por parte del Estado y los particulares, y la ausencia de cultura financiera. Bajo esta perspectiva, el sistema de emisión y rescate de billetes ${ }^{82}$ habría sido una estructura original e implacablemente diseñada, que pronto fracasó debido a la concatenación de diversos factores exógenos que acabaron por arrumbar un proyecto desafiante frente a la realidad local y la experiencia monetaria ${ }^{83}$. Sin embargo, un detallado análisis del modelo teórico de referencia y su contrastación con la iniciativa peruana de papel moneda añade a la explicación del fracaso el deficiente diseño teórico del proyecto.

Esta propuesta defiende que el modelo teórico de referencia fue la obra de Alonso Ortiz, mandada reimprimir en Lima en paralelo a la publicación de los decretos

80 CAmprubí, 1960, pp. 1-5 y 40-43.

81 El acta de la sesión celebrada por el Ayuntamiento el 24-XII-1821 en la sala Capitular de la municipalidad, presidida por José de la Riva Agüero junto con representantes del Ayuntamiento y los priores del Tribunal del Consulado, con el objeto de formalizar la hipoteca de 500.000 pesos para asegurar al banco emisor queda de hecho en suspenso sin formalizarse en el futuro. Acta de sesión de Cabildo de 24 de diciembre de 1821. Libro de Cabildos, acta, extendida a fojas 103 vuelta y 104. GAMIO, 2005, pp. 314-315.

82 Idea de un Banco Auxiliar. Lima, 1821. CDIP, Tomo XIII, Obra de Gobierno y Epistolario de San Martín, vol. I, pp. 248-265

83 Es la línea de explicación dada por la historiografía tradicional peruana desde el propio Unanue en la Memoria que presentara ante el Congreso en 1823 hasta la obra central ya citada de Camprubí. 
de creación de la nueva institución y de la puesta en marcha del sistema de emisión. La reimpresión se realizó en la Imprenta de los Huérfanos en el año de 1822, con el título Ensayo Económico sobre el sistema de la Moneda-Papel y sobre el Crédito Público. Se escribía contra algunas precauciones vulgares por D. José Alonso Ortiz el año de 1796, y con el mismo fin se reimprime en Lima, con adiciones sobre el Banco Auxiliar ${ }^{84}$. La obra tenía dos partes claramente diferenciadas. Una primera, correspondía a una fiel reproducción de la obra original de 1796, y una segunda de elaboración original bajo el título Adiciones al Ensayo sobre el Papel-moneda escrito por D. José Alonso Ortiz impreso en Madrid en 1796. Esta última, aparecía sin firma y estaba compuesta por una introducción y siete breves capítulos dedicados a especificidades de la realidad económica y financiera peruana.

Para argumentar esta propuesta considero pertinente entrar en el análisis de la segunda parte, con el objeto de detectar similitudes y desviaciones desde un punto de vista teórico y metodológico con respecto al modelo original.

La presentación remarcaba la pretendida armonía entre el proyecto del Banco Auxiliar del Perú y el Ensayo ${ }^{85}$, y reconocía su función como instrumento, a corto plazo, de auxilio para los fondos públicos y privados y, a largo plazo, de fomento del crecimiento económico. Las sucesivas adiciones a los capítulos correspondientes a la obra original incorporaban datos relacionados con la realidad monetaria del Perú y defienden los cambios realizados sobre el original en base a la singularidad de la realidad peruana.

El informe insistía en el principal problema monetario a superar, la escasez de numerario en circulación. Se describía la situación de absoluta desmonetización de la economía peruana con gran parte del país recurriendo al trueque y en la capital a los signos de plomo de las pulperías con el objetivo de suplir la falta de piezas inferiores a medio real. La razón, según el documento, estribaba en la desaparición de la circulación interior de los cuartillos de plata acuñados desde 1790 por medio de la extracción al exterior. Para lograr la paralización de las sacas se instaba a la acuñación de nuevos cuartillos de baja ley o de cobre y la emisión de papel moneda. En paralelo, se defendía la acuñación de "moneda fuerte", con el objeto de estimular la importación de artículos a bajo precio. En este punto se manifestaba una doble preocupación por el atesoramiento de "macromoneda" y la extracción sin contrapartidas de monedas inferiores de ocho reales ${ }^{86}$. La alternativa propuesta tenía tres niveles: primero, la acuñación de moneda superior a ocho reales con destino al comercio internacional, con alta ley y peso; segundo, la emisión de billetes inferiores a ocho reales y superiores a un real; y tercero, la introducción de moneda provincial de un real, medio y cuartillos de baja ley y peso. El primer nivel estaba dedicado a cubrir las necesidades del comercio internacional y evitar su inútil atesoramiento

84 Alonso Ortiz, 1822. Orden de reimpresión. Lima, 26-II-1822. AGN, Fondo Republicano, Ministerio de Hacienda, Caja 1, O.L. 48-5. Ejemplar disponible en la Biblioteca Nacional del Perú, Colección Zegarra, Código XZ-v.160-f.2. En la orden de reimpresión se reclama esta obra como el primer ensayo económico publicado en el Perú independiente.

85 "Si el proyecto del Banco hubiera sido concebido por el autor del ensayo, no hubiera guardado más conformidad con sus doctrinas". Alonso Ortiz, 1822, p. 165.

86 Ibídem, p. 167. 
en el interior; el segundo y tercer nivel iban dirigidos a suplir la demanda interior, y en este caso las sustanciales reducciones en sus valores intrínsecos debían desincentivar la exportación.

En la parte descriptiva, de forma genérica, el texto aludía a las ventajas del arbitrio al proporcionar recursos en un breve espacio de tiempo sin la necesidad de gravar al público con nuevas contribuciones. Esta idea rescataba reflexiones realizadas por Alonso Ortiz en el capítulo dedicado al crédito público, pero haciendo abstracción de las limitaciones relacionadas con este recurso en una situación de ausencia de paz y estabilidad. En la línea de reforzar la defensa del modelo en base a la teoría monetaria del Ensayo, el informe justificaba el sistema para un país que, por razones geográficas, sufría altos costes e inseguridad en la conducción de caudales entre distintos puntos. Para ello se planificó la extensión del giro del papel por las provincias interiores mediante la creación por parte del Banco de cajas subalternas en las principales ciudades. Sin embargo, el objetivo de reemplazar a largo plazo con papel el histórico drenaje de 17 millones de pesos en moneda macuquina -moneda americana de factura tosca elaborada mediante el método de acuñación a martillo-, ponía de manifiesto que el sistema nacía sin previos límites de emisión ni la consideración de la falta de una estructura económica moderna.

Con relación a las definiciones del proyecto bancario de emisión, la separación con el texto original comienza a ser patente. En primer lugar, entre las diversas definiciones de moneda-papel que redactó Alonso Ortiz no había referencias al tipo de billetes que emitió el Banco Auxiliar. Los billetes fueron efectivamente papel-moneda, lo que se alejaba del concepto utilizado por Alonso Ortiz de vales de tesorería.

En segundo lugar, la estabilidad del valor del papel moneda quedaba confiada, por una parte a la garantía ofrecida por el propio Banco a través de sus disponibilidades líquidas, aseguradas mediante amortizaciones trimestrales y un fondo estatal procedente de las Cajas Nacionales, y por otra al apoyo propuesto por el Estado permitiendo su aceptación en los pagos a razón del 50\% del importe en transacciones y contribuciones ${ }^{87}$. En tercer lugar, a las ventajas señaladas por Alonso Ortiz se sumaban otras tantas de carácter local relacionadas con la idiosincrasia peruana ${ }^{88}$. Por una parte, se reforzaba la idea del papel moneda como único suplente para el giro en un país como el Perú, sujeto a una intensa extracción de metálico casi directa de la mina a los puertos de embarque. De esta forma, el Banco Auxiliar, mediante el complejo sistema de amortizaciones trimestrales, al menos, dilataría la exportación del metal, y la introducción del papel estimularía el afloramiento de metal atesorado. Asimismo, la fijeza y frecuencia de estos plazos mantendría activos los caudales destinados al giro y estimularía la entrada en el circuito interior de cantidades monetarias de baja definición. Y por otra, presentaba al Banco del Perú como una institución bancaria de carácter nacional capaz de poder estimular el crecimiento económico a través de la expansión monetaria y el crédito, respondiendo así a ciertos límites de expansión sectorial relacionados con la falta de liquidez o

\footnotetext{
87 Ibídem, pp. 168-169.

88 Ibídem, pp. 171-176.
} 
la ausencia de adecuados instrumentos de intermediación financiera ${ }^{89}$. En cambio, en este punto la descripción superficial de potenciales beneficios, junto con el peregrino ejemplo que se acompañaba del Banco de Potosí alejaba al ensayo de la necesaria rigurosidad teórica. Esta impresión quedaba corroborada en el párrafo en el que se confunde la tasa de interés con el premio del papel moneda.

$\mathrm{Y}$ en cuarto lugar, las discrepancias con el Ensayo son absolutas en el punto en el que se recogen las precauciones para el establecimiento del papel moneda ${ }^{90}$. La primera establecía una relación de cuatro a uno entre el papel y el metálico, forzando el objetivo, a todas luces desmesurado, de cubrir en el primer año de emisión el déficit de acuñación entre 1822 y 1820 cifrado en torno a 2.500 .000 de pesos. En cuanto a la segunda precaución, eliminaba la advertencia de circunscribir la circulación de billetes a operaciones entre comerciantes. Señalaba que el giro peruano no se acomodaba al patrón europeo, de tal forma que el sistema necesariamente tenía que atender la demanda minorista mediante billetes de baja definición, como mínimo de un peso, que era la moneda común en América, y la que sufría mayores presiones de extracción. De esta forma, la circulación del dinero no se regularía a tres niveles, negociantes entre sí, negociantes y consumidores, y consumidores entre sí; sino en un único nivel en el que, desde una amplia base conformada mediante pequeñas porciones de consumos con origen en el comercio, las minas y la agricultura del interior, se irían formando masas de capitales progresivamente definidas en nominales superiores, vales y pólizas, en las principales plazas de negociación. Es decir, el sistema del Banco, consistente en la emisión de suplementos, amortización y emisión de vales con mayor nivel de denominación, acomodaría la circulación fiduciaria al ciclo natural del giro en la economía peruana. En definitiva, una relevante precaución desatendida alegando especificidades locales.

Con relación a la tercera precaución, el premio, se realizaba una adición ausente en el modelo de Alonso Ortiz, el cobro de una tasa de interés del dos por ciento a cargo de la emisión de suplementos en papel. Es decir, no se estudiaba ni analizaba la tasa de interés impuesta a los vales, sino al contrario, se explicaba la tasa que se cobraría a posteriori, a los particulares, por la aceptación de los billetes de baja denominación (suplementos de ocho, cuatro y dos reales). De esta forma el Banco se convertía en un gran prestamista que concedía créditos a particulares y administraciones públicas que de forma voluntaria aceptan un papel moneda con la obligación de reintegrarlo a partes iguales en metálico y papel en plazos trimestrales a un tipo de interés anual del $2 \%$. Una propuesta con el objetivo de aflorar metal atesorado a todas luces voluntarista. Este interés permitiría al Banco ir supliendo sus gastos administrativos y atender progresivamente a los siguientes tomadores de vales y pólizas de alta denominación (100 y 500 pesos) con intereses del 4, 5 y 6\%. Como puede observarse en el siguiente gráfico el modelo nunca logró pasar del primer nivel de emisión primaria ya que al fallar las sucesivas amortizaciones trimestrales, la circulación de vales de tesorería quedó en un hecho marginal.

\footnotetext{
89 Ibídem, pp. 174-175.

90 Ibídem, pp. 176-181.
} 
Gráfico 1. Estructura y volumen del papel moneda en circulación (8 de agosto de 1822).

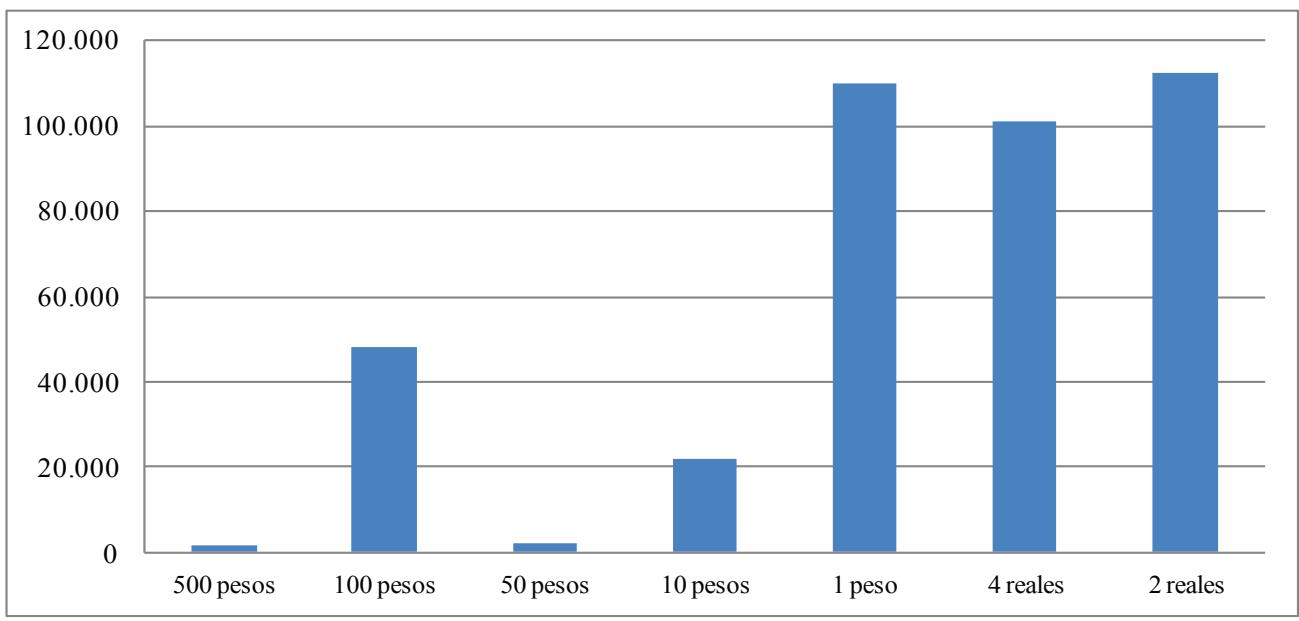

Fuente: Circulación de papel moneda [en pesos]. Lima, 1822.

AGN, Ministerio de Hacienda. O. L. 48-29.

Por último, la cuarta y quinta precaución, sobre los "fondos de reducción" y "extinción", confirmaban el divorcio total con respecto al modelo de referencia al no contemplar ninguna medida al respecto ${ }^{91}$.

Los diques de contención fueron más imaginarios que reales. En cuanto a los particulares, no se articularon garantías especiales por su posible doble condición de deudores, tomadores de suplementos en billetes, y acreedores, titulares de vales y pólizas. Este hecho hizo pensar que los mismos individuos estarían interesados en el cumplimiento de los plazos y condiciones de los reintegros. Por otra parte, y a modo de cautela para el caso en que el Estado precisase contraer nuevas deudas, se constituyó un aval en forma de hipoteca, que como ya he señalado, nunca fue satisfecho por parte de la Municipalidad y el Tribunal del Consulado, por valor de medio millón de pesos. Para agravar aún más la vulnerabilidad del modelo, el Estado a su vez nunca hizo efectivo su compromiso de dotación de un fondo de 500.000 pesos basado en la reforma de las Cajas Nacionales. Sin fondos de reducción y extinción la nueva institución quedaba reducida a una simple oficina fiscal de un Estado aún por definir.

En definitiva, un diseño bancario basado en una recepción parcial del Ensayo Económico de Alonso Ortiz, junto a la ausencia de una base económica que garantizase las reservas metálicas sobre las que sostener la expansión fiduciaria, condujeron al modelo a una rápida crisis de difícil reorientación. La operación bancaria y fiduciaria

\footnotetext{
91 "El Banco en su giro ordinario de suplementos y reintegros, no necesita fondo de reducción; pues en ninguno de sus plazos se obliga á amortizar más cantidad de la que están obligados á reintegrarle los que recibieron el suplemento; y siendo estos plazos tan frecuentes, no deben causar demérito a la estimación del papel". Ibídem, p. 179.
} 
surgió en medio de la guerra y las urgencias por obtener fondos y liquidez con los que mantener el esfuerzo bélico confirieron al modelo un perfil unilateralmente fiscal, convirtiendo los pretendidos aspectos de modernización monetaria en elementos puramente retóricos.

Desde el decreto de 13 de agosto de 1822, en que fue declarada la extinción del papel moneda, hasta la pérdida de rastro documental a partir de diciembre de 1823, el Banco sostuvo una agónica existencia dedicada a la amortización del papel moneda. A pesar del fracaso sus ecos todavía resonarían en el proyecto de establecimiento de un nuevo banco, en este caso como entidad particular de emisión y descuento, a iniciativa del Tribunal del Consulado a mediados de $1825^{92}$ y tomando como referencia el Banco de Descuentos de Buenos Aires. Sin embargo, la iniciativa no prosperó y la historia de la banca moderna en el Perú habría de esperar cuatro décadas después de declarada la independencia.

\section{CONCLUSIONES}

La guerra de independencia en el Perú abrió la posibilidad del debate en torno a las controversias monetarias y el modo de hacer frente al colapso del sistema monetario imperial. El Protectorado se enfrentó a la resolución de un difícil punto de partida, "máquinas sin plata", y a la necesidad imperiosa de poner en marcha iniciativas de nuevo cuño. El Banco Auxiliar de Papel Moneda se erigió en el esperado proyecto monetario que permitía al nuevo Estado sortear las dificultades del presente y crear las bases de un sistema monetario moderno. En febrero de 1822 la nueva institución comenzó su andadura, alentada de forma decisiva por el ministro de Hacienda Hipólito Unanue y diseñada por una pequeña comisión formada por representantes del Tribunal del Consulado, pero falta de una sólida base económica que resultaría relevante para explicar su prematuro fracaso.

El modelo proyectado adoptó como referencia teórica el Ensayo Económico sobre el sistema de moneda papel, obra de José Alonso Ortiz publicado en Madrid en 1796. Sin embargo, el análisis comparativo con la obra impresa en Lima en 1822 y que incluía una serie de adiciones, revelaba diferencias fundamentales con el modelo teóricamente asumido. Los "billetes" que emitió el Banco Auxiliar no guardan relación con los vales de tesorería del Ensayo Económico, y numerosas precauciones contempladas en la obra de Alonso Ortiz para el establecimiento del papel moneda, incluyendo la disponibilidad de un fondo de redención y extinción, fueron desatendidas en el proyecto peruano. Asimismo, no se tuvo en cuenta la precisa relación entre emisión y endeudamiento moderado, ni la restricción del proyecto a la esfera comercial. Desde una perspectiva de política monetaria, el objetivo forzado de cubrir mediante papel moneda un déficit monetario anual de dos millones y medio de pesos se antojó ilusorio y temerario. Y la puesta en marcha de un proyecto fiduciario sin base metálica ni mecanismos autorreguladores se manifestó aventurero.

92 CAmprubí, 1960, pp. 114-116. 
En definitiva, la planificación del Banco y del sistema de expansión fiduciaria se realizó desde parámetros muy distintos de los reflejados en el supuesto referente teórico. Ante la incapacidad del gobierno de elaborar por encargo un informe técnico con el que sostener el proyecto de papel moneda en el Perú, se optó por la reimpresión del Ensayo Económico de José Alonso Ortiz añadiendo unas adiciones, ligeras en lo teórico y contradictorias con la obra original, que convirtieron al modelo en inviable desde el mismo instante de su concepción.

\section{REFERENCIAS BIBLIOGRÁFICAS}

Alonso Ortiz, José

1796 Ensayo Económico sobre el sistema de la moneda-papel y sobre el crédito público. Madrid. Imprenta Real.

1822 Ensayo Económico sobre el sistema de la moneda-papel y sobre el crédito público. Se escribía contra algunas precauciones vulgares por D. José Alonso Ortiz el año de 1796, y con el mismo fin se reimprime en Lima, con adiciones sobre el Banco Auxiliar. Lima. Imprenta de los Huérfanos.

Anna, Timothy E.

2003 La caída del gobierno español en el Perú. El dilema de la independencia [1979]. Lima. Instituto de Estudios Peruanos.

CAMERon, Rondo

1974 La banca en las primeras etapas de la industrialización. Madrid. Tecnos.

CAmprubí, Carlos

1960 El Banco de la emancipación. Lima. Villanueva.

CANGa Argüelles, José

1968 Diccionario de Hacienda Pública [1826-1827]. Madrid. Instituto de Estudios Fiscales.

Cipolla, Carlo

1999 La odisea de la plata española. Barcelona. Crítica.

Colección Documental de la Independencia del Perú (CDip)

1971 Asuntos Económicos. Tomo XXI, vol. I. Lima. Comisión Nacional del Sesquicentenario de la Independencia del Perú.

1974 Los Ideólogos. Tomo I, vol. 7. Lima. Comisión Nacional del Sesquicentenario de la Independencia del Perú.

1974 Obra de Gobierno y Epistolario de San Martín, Tomo XIII, vol 1. Lima. Comisión Nacional del Sesquicentenario de la Independencia del Perú.

Contreras, Carlos

2004 El aprendizaje del capitalismo. Estudios de historia económica y social del Perú Republicano. Lima. IEP Ediciones.

2010 “La minería en el Perú en la época colonial tardía, 1700-1824”. En Contreras (ed.), Compendio de Historia Económica del Perú, Tomo III, Economía del período colonial tardio. Lima. Banco Central de Reserva del Perú - Instituto de Estudios Peruanos, pp. 103-162.

Снiск, Victoria

1990 La macroeconomía según Keynes. Una revisión de la teoría general. Madrid. Alianza Editorial. 
Chocano, Magdalena

2010 "Población, producción agraria y mercado interno, 1700-1824". En ConTRERAs (ed.), Compendio de Historia Económica del Perú. Tomo III. Economía del período colonial tardio. Lima. Banco Central de Reserva del Perú - Instituto de Estudios Peruanos, pp. 19-96.

Clément, Jean -Pierre

1979 Índices del Mercurio Peruano 1790-1795. Lima. Instituto Nacional de Cultura.

DANCUART, Pedro Emilio

1905 Anales de la Hacienda Pública del Perú. Tomo I. Lima. Imprenta de "La Revista".

De Haro, Dionisio

2006 La Reforma monetaria del Trienio Constitucional. De la política monetaria ilustrada al reformismo liberal. Madrid. Dykinson.

2011a "La política monetaria de San Martín en el Perú". Revista de Indias. Madrid, vol. LXXI, n 253 , pp. 793-823.

2011b "Guerra y moneda durante la Independencia del Perú, 1820-1824". Jahrbuch für Geschichte Lateinamerikas. Viena, nº 48, pp. 83-105.

Espinosa Montero, Álvaro

2001 "Oro, plata y mercurio, los nervios de la monarquía española”. Revista de Historia Económica. Madrid, n 3, pp. 503-538.

Fernández Marugán, F - Schwartz, P.

1978 "El Ensayo de José Alonso Ortiz. Monetarismo smithiano en la España de los Vales Reales”. En A. Otazu (ed.), Dinero y crédito (siglos XVI al XIX). Madrid. Moneda y Crédito, pp. 393-435.

FISHER, John

1977 Minas y mineros en el Perú colonial, 1776-1824. Lima. Pontificia Universidad Católica del Perú.

Flores GuZmán, Ramiro Alberto

2010 "Fiscalidad y gastos de gobierno en el Perú borbónico". En ConTreras (ed.), Compendio de Historia Económica del Perú. Tomo III. Economía del período colonial tardio. Lima. Banco Central de Reserva del Perú - Instituto de Estudios Peruanos, pp. 295-376.

FONTANA, Josep

1992 La crisis del Antiguo Régimen 1808-1833. Barcelona. Crítica.

Fuentes Quintana, Enrique - Perdices De Blas, Luis

1997 "Estudio Preliminar a la edición facsímil de la traducción de La Riqueza de las Naciones realizada por José Alonso Ortiz en 1794". Valladolid. Consejería de Cultura y Educación de la Junta de Castilla y León, pp. XVI-CXIV.

Gamio, Fernando

2005 La Municipalidad de Lima y la emancipación de 1821 [1944]. Lima. Municipalidad Metropolitana de Lima.

GARCíA-BAQUero, Antonio

2003 El comercio colonial en la época del Absolutismo Ilustrado: problemas y debates. Granada. Universidad de Granada.

Gelman, Jorge

2009 “Crisis postcolonial en las economías sudamericanas? Los casos del Río de la Plata y Perú”. En Llopis - Marichal (coords.), Latinoamérica y España 1800-1850. Un crecimiento económico nada excepcional. Madrid. Marcial Pons Historia, pp. 25-64. 
HAMnETT, Brian R.

2000 La política contrarrevolucionaria del virrey Abascal: Perú, 1806-1816. Lima. Instituto de Estudios Peruanos.

Hernández Andreu, Juan

1973 "La exposición de Diego de Gardoqui de 28 de julio de 1792. Un proyecto de fomento de las fuentes de riqueza nacionales y de liquidación de la Deuda Pública". Anales de

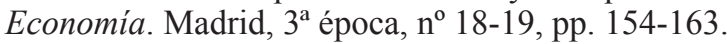

Hicks, John

1989 Métodos de economía dinámica. México. Fondo de Cultura Económica.

IRIGOIN, María Alejandra

2010 "Gresham a caballo: las raíces monetarias de la fragmentación política de la América española en el siglo XIX”. En Contreras - MAzzeo - Quiroz (eds.), Guerra, finanzas y regiones en la historia económica del Perú. Lima. Banco Central de Reserva del Perú, pp. 219-265.

Kindleberger, Charles P.

1988 Historia financiera de Europa. Barcelona. Crítica.

KLEIN, Herbert.

1998 The American Finances of the Spanish Empire. Royal Income and Expenditures in Colonial Mexico, Peru, and Bolivia, 1680-1809. Albuquerque. University of New Mexico Press.

López SoRIA, José Ignacio

1971 Ideología económica del “Mercurio Peruano”. Lima. Comisión Nacional del Sesquicentenario de la Independencia del Perú.

LYNCH, John

2009 San Martín. Soldado argentino, héroe americano. Barcelona. Crítica.

MaLdonAdo, Javier

2000 La formación del capitalismo en el Marco del Jerez. Madrid. Huerga y Fierro.

MARichal, Carlos

1999 La bancarrota del virreinato. Nueva España y las finanzas del imperio español, 17801810. México. Fondo de Cultura Económica.

MARTínez RiazA, Ascensión

1985 La prensa doctrinal en la Independencia del Perú: 1811-1824. Madrid. Cultura Hispánica.

MARX, Karl

1976 Contribución a la crítica de la economía politica [1859], versión castellana de J. Merino (segunda edición). Madrid. Lasgon.

Mazzeo, Cristina

2006 "Los comerciantes, el Consulado y los préstamos al gobierno republicano (Lima Perú, 1820-1840)". Revista Complutense de Historia de América. Madrid, vol. 32, pp. 63-85.

Mitre, Antonio

2004 El monedero de los Andes. Región económica y moneda boliviana en el siglo XIX. México. Instituto Mora.

O'Phelan Godoy, Scarlett

1988 Un siglo de rebeliones anticoloniales: Perú y Bolivia 1700-1783. Cuzco. Centro de Estudios Rurales Andinos Bartolomé de las Casas. 
PARKER, Geoffrey

1979 "El surgimiento de las finanzas modernas en Europa (1500-1730)". En Cipolla (ed.), Historia económica de Europa (2). Siglos XVI y XVII. Barcelona. Ariel, pp. 410-465.

PAscual, Pere - Sudrià, Carles

2008 "Industrialización, desarrollo financiero y oferta monetaria en Barcelona a mediados del siglo XIX”. Investigaciones de Historia Económica. Madrid, nº 12, pp. 45-77.

Prieto, Enrique - De Haro, Dionisio

2004 Las reformas monetarias en la primera mitad del siglo XIX. Una aproximación a la historia monetaria de España desde el trienio constitucional hasta la Ley monetaria de 1848. Madrid. Dykinson.

2010 Historia monetaria de la España contemporánea. Madrid. Delta Ediciones.

2012 "La reforma monetaria del trienio Liberal en España, 1820-1823: modernización y límites". América Latina en la Historia Económica. México, n 38, pp. 131-161.

Quiroz, Alfonso W.

1993 Deudas olvidadas. Instrumentos de crédito en la economía colonial peruana 17501820. Lima. Pontificia Universidad Católica del Perú.

1995 “Desarrollo de la Banca Central en Perú (1875-1935)”. En Tedde - Marichal (coords.), La formación de los Bancos centrales en España y América Latina, vol. II. Madrid. Banco de España, pp. 103-117.

Riva AgüERo, José de la

1953 Historia del Perú. Lima. Lumen.

SALINAS, Alejandro

2011 Cuartos y billetes. Crisis del sistema monetario peruano 1821-1879. Lima. Banco Central de la Reserva del Perú.

SARDÀ, Joan

1998 La politica monetaria y las fluctuaciones de la economía española en el siglo XIX. [1948]. Barcelona. Alta Fulla.

SMith, Adam

1981 Investigación sobre la naturaleza y causas de la riqueza de las naciones. [1776]. Versión castellana de Gabriel Franco de la edición de E. Cannan (segunda reimpresión). México. Fondo de Cultura Económica.

Sмiтн, Robert Sidney

1973 “La Riqueza de las Naciones en España e Hispanoamérica”. [1957]. Hacienda Pública Española. Madrid, nº 19, pp. 240-265.

SuÁREZ, Margarita

2001 Desafios transatlánticos. Mercaderes, banqueros y el estado en el Perú virreinal, 1600-1700. Lima. Pontificia Universidad Católica del Perú - Fondo de Cultura Económica - Instituto Francés de Estudios Andinos.

TedDE DE LoRCA, Pedro

1988 El Banco de San Carlos (1782-1829). Madrid. Alianza.

TEPASKE, John J.

1986 "General Tendencies and Secular Trends in the Economies of Mexico and Peru: The View from the Cajas of Mexico and Lima". En Jacobsen - Puhle (eds.), The Economies of Mexico and Peru During the Late Colonial Period, 1760-1810. Berlín. Colloquium, pp. 316-339. 
VAdiLlo, José Manuel de

1846 Reflexiones sobre la urgencia de remedio a los graves males que hoy se padecen en España por causa de muchas monedas que circulan en ella. Cádiz. Imprenta de Manuel Bosch.

VILAR, Pierre

1980 "Los primitivos españoles del pensamiento económico: cuantitativismo y bullonismo", Crecimiento y desarrollo. Economía e historia. Reflexiones sobre el caso español. Barcelona. Ariel, pp. 175-207. 